\title{
LEDDERHOSE'S DISEASE: CASE REPORT
}

Diogo Rios de Avila (UFMT, Sinop, MT, Brasil), Allana Campos Alves (UFMT, Sinop, MT, Brasil), Andressa Gabrielly Rodrigues Beserra (UFMT, Sinop, MT, Brasil), Gabriel Ribeiro Leão Barroso (UFMT, Sinop, MT, Brasil), Gabriel Freitas de Campos (UFMT, Sinop, MT, Brasil), Fabiana de Castro Machado (UFMT, Sinop, MT, Brasil), Heloisa Maria Lopes Scarinci (UFMT, Sinop, MT, Brasil), Flavio Fernandes Barboza (UFMT, Sinop, MT, Brasil)

\section{BACKGROUND}

Ledderhose's disease is part of a group of benign fibroblast proliferations called fibromatosis, which superficially affects the plantar fascia and, in some cases, the hands. It is a rare disease, with higher incidence in males aged 30-50 years. Its etiology is unknown, but there is multifactorial evidence, including genetics, microvascular trauma, use of anticonvulsants and immunological reactions. It is characterized by subcutaneous nodules of slow proliferation, more frequently located in the central and medial portions of the plantar fascia, and up to half of the cases affects both feet. Most clinical conditions are asymptomatic, but pain can be triggered after periods of walking. Also, when the nodules invade structures like nerves and muscles, symptoms may become more specific.

\section{CASE REPORT}

A 60-year-old man has been presenting nodular lesions on both legs for the past 10 years. He complains of bilateral pain in the plantar region when performing extensive walking, mainly in the location of the nodules. The patient, who had previous hypertension and is neither a smoker nor an alcoholic, is currently

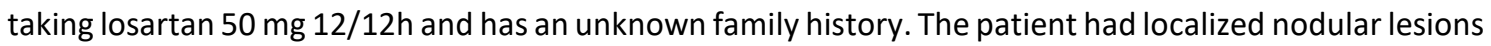
in the bilateral plantar fascia, painless on physical examination(figure1 and 2). After the clinical diagnosis, associating anamnesis with physical examination, prescribed treatment involved the use of pain relief insoles, stretching the plantar fascia and guidance on the benignity of the condition.

\section{CONCLUSION}

Although rare, Ledderhose's disease is the second most common superficial fibromatosis and should be remembered by the rheumatologist when painful complaints associate with plantar nodules. The diagnosis is eminently clinical, with no need for additional tests, and risk factors related to diabetes mellitus, epilepsy, keloids, anticonvulsant abuse, Dupuytren's disease and even alcoholic liver disease should be investigated. 